\title{
HERBAL COMPRESS BALL DALAM MENURUNKAN NYERI GOUT ARTHRITIS
}

\author{
Herbal Compress Ball to Reduce Gout Arthritis Pain \\ Tasnim*, Nirva Rantesigi, Ulfa Sufyaningsi, Putri Pratiwi Buria \\ Poltekkes Kemenkes Palu \\ *Email korespondensi: tasnimpoltekkespalu@ gmail.com,
}

\begin{abstract}
ABSTRAK
Pendahuluan: Gout Athitis merupakan penyakit metabolic yang di sebabkan oleh kelebihan kadar senyawa urat di dalam tubuh, baik karna produksi berlebih, eliminasi yang jarang, atau peningkatan asupan purin. Salah satu terapi non-farmakologis untuk menurunkan skala nyeri otot adalah dengan terapi Herbal Compress Ball yang efeknya berasal dari konduksi panas yang dapatmeningkatkan aliran darah regional ke daerah nyeri, efek analgesik berasal dari bahan-bahan herbal dan minyak asiri aromaterapi memberi efek relaksasi. Tujuan:Dapat mengidentifikasi pengaruh Herbal Compress Ball dalam menurunkan nyeri GoutArthritis. Metode Penelusuran: basis data yang digunakan dalam studi literatur yaitu Publish Or Perish, Google Scholar, dan Google.Hasil jurnal: Herbal Compress ball lebih efektif daripada terapi standar yang direkomendasikan pada pasien dengan masalah muskuloskelektal pengobatan dengan herbal compress ball dapat mengurangi tingkat rasa nyeri serta dapat meningkatkan kualitas hidup. Ini dapat dianggap sebagai opsi alternatif untuk memperbaiki gejala kondisi ini terutama ketika efek samping dari perawatan lain seperti NSAID. Kesimpulan: Setelah dilakukan review dari beberapa jurnal didapatkan bahwa herbal compress ball dapat menggurangi nyeri muskuloskletal dan mebuat relaksasi.Saran: diharapkan hasil penelitian ini bisa menambah pengetahuan dan wawasan peneliti selanjutnya tentang intervensi keperawatan yang dapat mengurangi nyeri pada gout arthritis.
\end{abstract}

Kata kunci: Gout arthritis, Nyeri, Herbal Compress ball;

\begin{abstract}
Introduction: Gout Athitisis a metabolic disease caused by excess levels of uric compounds in the body, either due to overproduction, infrequent elimination, or increased purine intake. One of the nonpharmacological therapies to reduce the scale of muscle pain is the Herbal Compress Ball therapy whose effect comes from heat conduction which can increase regional blood flow to the pain area, the analgesic effect comes from herbal ingredients and aromatherapy essential oils to give a relaxing effect. Objective: To identify the effect of the Herbal Compress Ball in reducing GoutArthritis pain. Research method: the database used in the literature study is Publish or Perish, Google Scholar, and Google. Journal results: Herbal Compress ballmore effective than standard therapy recommended in patients with musculocelectal problems. Treatment with herbal compress balls can reduce pain levels and can improve quality of life. This can be considered an alternative option for improving the symptoms of this condition especially when it is a side effect of other treatments such as NSAIDs. Suggestion: After reviewing several journals, it was found that herbal compress balls can reduce painmusculoskletal and create relaxation. Suggestion dIt is hoped that the results of this study can add to the knowledge and insight of future researchers about nursing interventions that can reduce pain in gouty arthritis.
\end{abstract}

Keywords : Arthritis Gout, Pain, Herbal Compress ball;

https://doi.org/10.33860/mnj.v1i2.266

(C) 2020 by the authors. Submitted for possible open access publication under the terms and conditions of the Creative Commons Attribution (CC BY SA) license (https://creativecommons.org/licenses/by-sa/4.0/). 


\section{PENDAHULUAN}

Gout Arthitis atau yang sering orang awam katakan asam urat merupakan pembentukan kristal pada persendian, akibat tingginya kadar asam urat dalam darah. Asam urat merupakan sisa dari sel-sel tubuh yang mati, sehigga sel-sel tubuh yang mati melepas purin. Dan asam urat menumpuk di persendian yang membentuk garam urat (monosodium urate). Penumpukan kristal tersebut mengakibatkan kerusakan pada daerah persendian sehingga dapat menimbulkan nyeri kadar asam urat normal pada pria berkisar 3,5-7 $\mathrm{mg} / \mathrm{dl}$ dan pada perempuan 2,6-6 mg/dl. ${ }^{1}$ Prevalensi gout di dunia menurut WHO mengalami kenaikan dengan jumlah $(33,3 \%)$. Berdasarkan hasil Riskesdas Indonesia tahun 2018 jumlah penyakit sendi berdasarkan diagnosis dokter di Indonesia mencapai 7,3\% dan berdasarkan diagnosis tenaga kesehatan mencapai $11,9 \%$. Dari data yang diperoleh dari Dinas Kesehatan Sulawesi Tengah, jumlah penyakit Gout Arthitis (74\%). ${ }^{3}$

Gejala utama yang dirasakan oleh penderita gout arthritis adalah nyeri pada persendian yang disebabkan oleh penumpukan Kristal. Nyeri merupakan mekanisme pertahan tubuh manusia yang dapat merasakan bahwa tubuh seseorang mengalami masalah penurunan kemampuan musculoskeletal karena nyeri sendi dapat berdampak pada penurunan aktivitas pada sesorang. Aktivitas yang dimaksud antara lain makan, minum, berjalan, mandi, buang air besar, dan buang air kecil. ${ }^{4}$

Tingkat kejadian nyeri yang dialami oleh seseorang sangat sering terjadi, maka membutuhkan terapi untuk mengatasi nyeri. Dalam penatalaksanaan nyeri ada berbagai macam terapi yang bisa diberikan yaitu seperti (1) terapi farmakologi: opioid, obat antiinflamasi non-steroid (NSAID), parasetamol, analgesik epidural, entonoks, nefopam, antikonvulsan, antidepresan, dan kortikosteroid, (2) terapi contract relaxstretching, (3) terapi pedalexercise under compression, (4) terapi infra merah, (5) terapi horticultura, (6) mind body therapy, (7) terapi pijat, (8) terapi acupuncture, (9) terapi kompres, (10) terapi Herbal Compress Ball.

Pemberian terapi harus di perhatikan dengan benar karena setiap orang sangat rentan dengan komplikasi, maka perawat dibutuhkan untuk berperan dalam merawat dan membantu meringankan biaya serta mengurangi efek pengobatan farmakologi dengan menggunakan terapi modalitas. Salah satu terapi modalitas yang bisa diaplikasikan adalah dengan cara kompres. Kompres merupakan tindakan mandiri yang dilakukan perawat dalam menurunkan suhu tubuh dan mengurangi nyeri, baik itu kompres dingin maupun kompres hangat.

Pemberian terapi Herbal Compress Ball terhadap tubuh yaitu meningkatkan aliran darah kebagian tubuh yang mengalami cedera, meningkatkan pengiriman leukosit dan antibiotik ke daerah yang nyeri, meningkatkan pergerakan zat sisa dan nutrisi, meningkatkan relaksasi otot dan mengurangi nyeri akibat kekakuan otot. ${ }^{5}$

Terapi Herbal Compress Ball atau Luk Prakob telah digunakan di Thailand selama ratusan tahun sebagai terapi tradisional Thailand atau pun sebagai terapi modalitas yang berdiri sendiri dalam pengobatan muskuloskletal dan rehabilitatif. Efek Herbal Compress Ball berasal dari konduksi panas untuk meningkatkan aliran darah regional ke daerah yang terkena, anti inflamasi efek dari bahan herbal, relaksasi efek minyak atsiri aromatik dari bahan herbal. Kandungan Hebal Compress Ball bervariasi tergantung tersedianya ramuan tumbuhan dari setiap daerah. Herbal Compress Balljuga sering di aplikasikan hanya denganberbahan jahe, dari hasil penelitian kompres herbal dengan jahe member efek pemanasan, merangsang, dan relaksasi bagi tubuh dengan berbagai kondisi kesehatan, terutama pada pasien yang mengalami nyeri gangguan sistem muskuloskeletal. ${ }^{6}$

Jahe (zingiber) mengandung sekitar 1-2\% minyak asiri dan 5-8\% bahan resin, pati, dan getah. Minyak jahe yang memberi sifat aromatik pada jahe mengandung campuran lebih dari 20 unsur. Kunyit (curcumalonga dan curcuma domestic) yang juga merupakan salah satu dari bahan Herbal Compres Ball yang memiliki khasiat antiradang, antioksidan, antitukak, antimutagenik, dan antibakteri. Minyak esensial dalam kunyit memberikan efek aroma pedas dan rasa pedas yang tajam yang berfungsi untuk menghangatkan. Minyak esensial dalam kunyit didapatkan dari distilasi uap, metodenya sama dengan jahe. Saat semua bahan dipadukan dalam kompres maka akan memberikan khasiat masingmasing pada tubuh yang sakit, termasuk pikiran yang stres agar rileks dan membantu menyelesaikan masalah pernafasan saat menghirup wangi yang menyegarkan dari kompres. ${ }^{7}$ 
Berdasarkan penelitian oleh Dhippayom (2015), Chiranthanut (2014) dan Jurairat (2017 dan 2018) Penelitian ini dilakukan di Thailand kepada pasien yang mengalami nyeri rematik dan asam urat, pasien dengan nyeri muskuloskletal dan pasien dengan nyeri myfascial pain syndrome penelitian ini menunjukkan hasil yang baik dalam menurunkan nyeri. Pada penelitian ini juga dikatakan bahwa Herbal Compress Ball telah tercantum dalam daftar obat Esensial Nasional Thailand untuk otot terkilir, nyeri sendi, dan nyeri otot.

Berdasarkan latar belakang tersebut, review mencoba melakukan studi literature pada beberapa jurnal penelitian untuk mengetahui lebih mendalam yang berhubungan dengan efektifitas.

\section{METODE PENELUSURAN}

Penelusuran studi literatur ini dilakukan melalui Publish Or Perish dan website google scholardan dengan pembatasan waktu 2014 sampai dengan 2019. Kata kunci yang digunakan dalam pencarian jurnal: "Pengaruh herbal compress balldalam menurunkan nyeri gout arthritis"'"effect of herbal ball compresses in reducing gout arthritis pain"

\section{HASIL PENELITIAN}

Berdasarkan hasil penelusuran jurnal yang dilakukan, maka akan dibuat analisis jurnal yang terdiri dari peneliti (tahun \& judul), tujuan penelitian, desain penelitian, responden, pengumpulan data dan hasil penelitian.

Penelitian yang dilakuakan Loince etall., (2018) Pengaruh Herbal Compress Ball Terhadap Penurunan Nyeri sendi Pada Lansia Di Upt Pelayanan Sosial Lanjut Usia Binjai Tahun 2018, dengan tujuan penelitian Untuk mengetahui bagaimana pengaruh Herbal Compress Ball terhadap penurunan nyeri sendi pada lansia menggunakan desain penelitian ekspermental populasi yang diteliti sebanyak 15 lanjut usia, data dikumpulkan meliputi nama atau inisial responden, jenis kelamin, berumur mulai 60 tahun,lansia yang mengalami nyeri pada otot, tidak memiliki masalah yang terdapat dalam kontra indikasi pemberian Herbal Compress Ball, tidak mengalami komplikasi penyakit, pengukuran skala nyeri pada otot ditulis dilembar observasi dengan menggunakan pengukuran skala nyeri Wong-Baker FACES Rating Scale yang dilakukan sebelum dan sesudah intervensi. Pada hasil penelitian didapatkan bahwa
Berdasarkan hasil uji wilcoxon sign rank test, diperoleh hasil analisis statistic $\mathrm{p}$ value $=0.000$, dimana nilai $\mathrm{p}<0.05$, yang berarti ada pengaruh signifikan dari intervensi Herbal Compress Ball terhadap penurunan nyeri otot pada lansia di UPT Pelayanan Sosial Lanjut Usia Binjai tahun 2018

Penelitian yang dilakukan Natthakarn et all.,(2014)., Thai Massage, and Thai HerbalCompress versus Oral Ibuprofen in Symptomatic Treatment of Osteoarthritis of the Knee: A Randomized Controlled Trial dengan tujuan penelitian untuk menganalisis respon klinis terhadap pijat ala Thailand (TM) dan kompresi herbal Thailand (THC) untuk mengobati osteoarthritis (OA) lutut dibandingkan dengan ibuprofen oral yang dilakukan pada 60 pasien menggunakan desain penelitian randomized controlled trial data yang dikumpulkan nama, umur, jenis kelamin, pekerjaan, Mereka berusia di atas 45 tahun dan telah didiagnosis dengan OA lutut unilateral atau bilateral sesuai dengan kriteria American College of Rheumatology selama lebih dari tiga bulan. Peserta harus mampu berjalan. Hasil penelitannya menujukan bahwa Herbal Compress Ball sama baiknya dengan penggunaan obat ibuprofen dalam menurunkan nyeri osteoarthritis.

Penelitian yang dilakukan Orapin etall.,(2019)., The evectiveness of traditional Thai massage versus massage with herbal compress among elderly patients with low back pain: A randomised controlled trial dengan tujuan Untuk menentukan evefektivitas termasuk kompres herbal dalam rejimen pijat tradisional Thailand untuk perawatan nyeri punggung bawah pada lansia penelitian ini menggunkan metode randomized controlled trial yang dilakuan pada 140 pasien dengan nyeri punggung bawah kronis, data dikumpulkan yaitu : umur, jenis kelamin, pekerjaan partisipan berusia di atas 60 tahun ,mereka yang mampu berkomunikasi dalam bahasa Thailand dan telah didiagnosis dengan nyeri punggung bawah kronis (berlangsung selama setidaknya 12 minggu) dan Nyeri diukur sebelum dan sesudah dilakukan dilakukan intervensi menggunakan VAS (skala analog Visual) didapatkan hasil penelitian Tidak ada perbedaan yang signifikan secara statistikdalam hasil primer dan sekunder antara kedua kelompok studi (p-value> 0,05). Meskipun peningkatan diamati untuk kedua kelompok dalam intensitas nyeri, kecacatan, kualitas hidup, dan kinerja 
punggung.Namun, kesamaan dalam peningkatan besar untuk setiap pengobatan menunjukkan kesetaraan dan kemungkinan efektivitas yang sama dari TTM dan TMH yang membutuhkan verifikasi dalam penelitian masa depan.

Penelitian yang dialakukan Jurairat etall.,(2018).,Effectiveness of hot herbal compress versus topical diclofenac in treating patients with myofascial pain syndrome dengan tujuan untuk mengetahui efektivan kompres herbal panas versus diklofenak topical dalam merawat pasien dengan sindrom nyeri myofascial menggunakan desain penelitian randomized controlled trial yang dilakukan pada 60 pasien dengan MPS pada otot trapezius atas berdasarkan diagnosis klinis, data yang dikumpulakan meliputi: nama inisial responden, jenis kelamin, umur antara 25 dan 60 tahun riwayat didiagnosis dengan syndrome nyeri myfascial pengukuran nyeri: nyeri diukur sebelum dan sesudah dilakukan dilakukan intervensi CROM (Cervical Range of Motion) dan PPT (Pressure Pain Threshold) didapatkan hasil penelitian Data hasil VAS menunjukkan kompres herbal panas lebih kuat daripada diklofenak topikal. Skor VAS untuk kompres herbal panas meningkat sebesar 59,43\% (hari 16) dan 98,38\% (tindak lanjut). Skor kelompok diklofenak topikal menunjukkan potensi yang lebih kecil daripada kelompok kompres herbal dengan peningkatan persentase pada awal 46,46\% (hari 16) dan 67,50\% (tindak lanjut) ( $\mathrm{P}<0,01)$.

Penelitian yang dialakukan Jurairat et all.,(2017).,The Distinction of Hot Herbal Compress, Hot Compress, and Topical Diclofenac as Myofascial Pain Syndrome Treatment yang bertujuan untuk menguji kemanjuran kompres panas dalam pengobatan sindrom nyeri myofascial pada trapezius atas dibandingkan dengan nonsteroid.Menggunakan metode penelitian randomized controlled trial yang dialakukan pada 90 pasien didiagnosis dengan sindrom nyeri myofascial di trapezius atas oleh dokter. data yang dikumpulan meliputi: nama inisial responden, jenis kelamin, umur, riwayat penyakit, lokasi nyeriPasien dengan sindrom nyeri myofascial di trapezius atas berusia antara 25 dan 65 tahunLebih dari 3 bulan gejala Didiagnosis dengan sindrom nyeri myofascial. Nyeri diukur sebelum dan sesudah dilakukan dilakukan intervensi CROM (Cervical Range of Motion) dan PPT (Pressure Pain Threshold) Hasil penelitian ini menunjukkan bahwa semua 3 pilihan pengobatan berkhasiat dalam mengurangi tingkat rasa sakit, meningkatkan CROM, meningkatkan PPT, dan meningkatkan kualitas hidup. Namun, pengobatan kompres herbal panas berkontribusi pada tingkat nyeri yang lebih rendah dan CROM dan PPT yang lebih tinggi. Oleh karena itu, dapat disimpulkan bahwa pengobatan dengan kompres herbal panas cenderung menjadi pilihan yang lebih baik daripada kompres panas atau gel diklofenak topikal.

\section{PEMBAHASAN}

Tingkat kejadian nyeri yang dialami oleh seseorang sangat sering terjadi, maka membutuhkan terapi untuk mengatasi nyeri. Dalam penatalaksanaan nyeri ada berbagai macam terapi yang bisa diberikan yaitu seperti terapi Herbal Compress Ball.

Herbal Compress Ball adalah pengobatan tradisional dan rehabilitasi untuk sindrom menyakitkan pada gangguan sistem muskuloskletal dengan menggunakan bahan-bahan herbal. Bahanbahan herbal yang dibungkus dalam bentuk bola kompres yang hangat menjadi aktif termasuk minyak aromatik dan memberi efek analgesik saat di aplikasikan pada bagian tubuh tertentu yang mengalami nyeri. ${ }^{8}$

Efek Herbal Compress Ball berasal dari konduksi panas yang meningkatkan aliran darah regional ke daerah yang terkena, efek anti inflamatori berasal dari bahan-bahan herbal dan minyak asiri aromaterapi memberi efek relaksasi. Agar mencapai semua efek ini Herbal Compress Ball harus dikukus selama 10-15 menit sebelum penggunaan untuk memungkinkan konduksi panas mempermudah pelepasan zat aktif dan minyak asiri dari bahan herbal. ${ }^{9}$

Berdasarkan penelitian yang dilakukan oleh (Chiranthanut dan Hanprasertpong 2014) penelitian ini dilakukan terhadap 60 pasien dari kedua jenis kelamin yang berusia diatas 45 tahun yang telah didiagnosis Osteoathritis lutut sesuai kriteria American College of Rheumatologiselama lebih dari tiga bulan. Dalam penilitian ini, herbal compress ball dilakukan dengan aplikasi lembut sepanjang titik akupuntur untuk memastikan bahwa kemajuan klinis tidak dikacaukan dengan prosedur menekan yang meniruthai massage. herbal compress ball dapat 
memberikan efek teraupetiknya melalui beberapa mekanisme. Pertama, aplikasi panas topical terapi panas topical dapat menimbulkan efek hangat efek stimulasi kutaneus berupa sentuhan yang dapat menyebabkan terlepasnya endorphin, sehingga memblokir transmisi stimulasi nyeri.Selain, itu peningkatan suhu dalam otot rangka dan jaringan lunak disekitar lutut di postulasikan terkait dengan peningkatan aliran darah, yang mengarah pada eliminasi mediator inflamasi dari jaringan lutut panas juga meningkatkan ekstensibilitas jaringan ikat dan rentang gerakan sendi. Kedua, aplikasi lembut herbal compress ball sepanjang titik akupresur juga berkontribusi pada efek analgesik dan antiinflasmasi yang terdapat dalam kandungan bahan herbal dalam herbal compress ballseperti Kunyit (Curcuma longa), serai (Cymbopogon citratus), jahe (Zingiber cassumuna)r, Croton roxburghii, asam jawa (Tamarindus indica),jeruk nipis (Citrus hystrix), tanaman sembung (Blumea balsamifera), tanaman legundi (Vitex trifolia) dan kapur barus .

Dalam perbandingan antar kelompok ketiga modalitas memberikan kemanjuran klinis yang hampir sebanding setelah tiga minggu pengobatan OA lutut. Namun peningkatan terbesar, ditemukan dalam kelompok herbal compress ball. Selain itu pendapat dokter yang secara keseluruhan lebih baik dari perbaikan dalam herbal compress ball dibandingkan dengan thai massage, dan secara signifikan peningkatan yang lebih baik dari indeks fungsional Lequesne yang mendukung herbal compress ball dibandingkan dengan ibuprofen, dan tidak ada efek samping yang dilaporkan dalam kelompokherbal compress ball.

Herbal Compress Ball juga sering di aplikasikan hanya denganberbahan jahe, dari hasil penelitian kompres herbal dengan jahe member efek pemanasan, merangsang, dan relaksasi bagi tubuh dengan berbagai kondisi kesehatan, terutama pada lansia yang mengalami nyeri gangguan sistem musculoskeletal. ${ }^{6}$

Jahe (zingiber) mengandung sekitar 1-2\% minyak asiri dan 5-8\% bahan resin, pati, dan getah. Minyak jahe yang memberi sifat aromatik pada jahe mengandung campuran lebih dari 20 unsur. Kunyit (curcumalonga dan curcuma domestic) yang juga merupakan salah satu dari bahan Herbal Compres Ball yang memiliki khasiat anti radang, antioksidan, anti tukak, anti mutagenik, dan antibakteri. Minyak esensial dalam kunyit memberikan efek aroma pedas dan rasa pedas yang tajam yang berfungsi untuk menghangatkan. Minyak esensial dalam kunyit didapatkan dari distilasi uap, metodenya sama dengan jahe. Saat semua bahan dipadukan dalam kompres maka akan memberikan khasiat masingmasing pada tubuh yang sakit, termasuk pikiran yang stres agar rileks dan membantu menyelesaikan masalah pernafasan saat menghirup wangi yang menyegarkan dari kompres. ${ }^{7}$

Berdasarkan penelitian yang dilakukan oleh (Baeha, Pujiatuti, dan pane 2018) yang dilakukan terhadap 15 orang responden, didapatkan data bahwa ada perubahan skala nyeri otot pada responden sebelum dan setelah dilakukan intervensi herbal compress ball, Pada tahap pre intervensi herbal compress ballmayoritas nyeri otot yang dialami responden dengan kategori nyeri sedang (skala nyeri 4-6) sebanyak 9 orang (60\%) responden dan nyeri berat terkontrol (skala nyeri 7-9) sebanyak 6 orang (40\%) responden. Pada tahap post intervensi herbal compress balldidapatkan responden tidak merasakan nyeri (skala nyeri 0) sebanyak 9 orang $(60 \%)$ responden dan sebanyak 6 orang $(40 \%)$ responden dengan kategori nyeri ringan (1-3). ${ }^{10}$

Nyeri pada otot dapat berkurang akibat dari efek pemberian terapi panas terhadap tubuh sehingga meningkatkan aliran darah ke bagian tubuh yang mengalami cedera, meningkatkan pengiriman leukosit dan antibiotik ke daerah luka, meningkatkan relaksasi otot dan mengurangi nyeri akibat spasme atau kekakuan, meningkatkan aliran darah dan meningkatkan pergerakan zat sisa dan nutrisi. ${ }^{5}$

Terapi panas yang mengandung jahe secara fisiologis, menurunkan nyeri pada tahap transduksi, dimana pada tahapan ini jahe memiliki kandungan gingerol yang mengandung siklooksigenase yang bisa menghambat terbentuknya prostaglandin sebagai mediator nyeri, sehingga terjadi penurunan nyeri pada daerah yang bermasalah. ${ }^{11}$

Hasil penelitian yang dilakukan oleh (Laosee et al. 2020) tentang The evectiveness of traditional Thai massage versus massage with herbal compress among elderly patients with low back pain: A randomised controlled. Dalam hal perbandingan hasil (baik primer dan sekunder) antara pijat tradisonal thailand dan herbal compress ball pada 15 
minggu sesi pengobatan, setelah perawatan (pada minggu ke 15). Namun, kesamaan dalam peningkatan besar untuk setiap pengobatan dan kemungkinan sama efektivas pijat tradisonal thailand dan herbal compress ball yang dapat digunakan untuk masa depan. ${ }^{12}$

Berdasarkan penelitian yang dilakukan oleh (Boonruab et al. 2019) tentang Effectiveness of hot herbal compress versus topical diclofenac in treating patients with myofascial pain syndrome pada 60 pasien sindrom nyeri myfasical pada otot trapezius. herbal compress ballselama 20 menit bergantian dan suhu permukaan 450 C.herbal compress balldilakukan 6 kali dan tindak lanjut setelah 2 minggu. Pasien dalam kelompok 2 menerima antiinsteroid nonsteroid yang diberikan sendiri setiap hari sebagai $2 \mathrm{mg}$ gel diklofenak topikal $1 \%$ diterapkan pada titik pemicu tiga kali sehari selama 2 minggu dengan tindak lanjut. setelah 2 minggu menujukan hasil bahwa hasil VAS (Visual analogue scale) menunjukkan herbal compress ball lebih kuat daripada diklofenak topikal. Skor VAS untuk kompres herbal panas meningkat sebesar 59,43\% (hari 16) dan 98,38 \% (tindak lanjut). hasil ini mendokumentasikan bahwa herbal compress ball dapat sercara efektif digunakan sebagai pengobatan alternative MPS sebagai perawatan kesehatan primer.

Boonruap sebelumnya telah melakukan penelitian untuk menguji kemanjuran herbal compress ball dibandingkan dengan kompres panas dan gel diklofenak topikal dalam pengobatan pasien dengan sindrom nyeri myofascial di trapezius atas. Pengobatan herbal compress ball berkontribusi pada tingkat nyeri yang lebih rendah dan CROM (Cervical Range of Motion) dan PPT (Pressure Pain Threshold) yang lebih tinggi. Oleh karena itu, pengobatan dengan herbal compress ballcenderung menjadi pilihan yang lebih baik daripada kompres panas atau gel diklofenak topical. ${ }^{13}$

Berdasarkan penelitian diatas bahwa penggunaan Herbal Compress Ball sangat baik dianjurkan sebagai terapi alternatif dalam menurunkan nyeri pada sindrom nyeri myofascial di trapezius atas dan nyeri pada Osteoarthritis serta nyeri pada otot. Penggunaan terapi Herbal Compress Ball bermanfaat dalam mengurangi dampak negatif penggunaan terapi farmakologi dan juga penggunann Herbal Compress Ball tidak memiliki efek samping.

\section{SIMPULAN DAN SARAN}

Herbal Compress Ball merupakan terapi komplementer yang bisa dijadikan sebagai salah satu intervensi keperawatan dalam mengatasi nyeri pada pasien nyeri otot, nyeri sendi, nyeri osteoarthritis, nyeri punggung bawah dan myofascial pain syndrome. Pemilihan teknik cocok sebagai intervensi untuk mengurangi nyeri karena beberapa penelitian membuktikan bahwa teknik ini efektif dalam menurunkan nyeri, teknik yang sederhana, dan mudah dilakukan. Diharapkan perawat dapat memberikan Herbal compress ballsebagai intervensi non farmokologi yang direkomendasikan pada pasien dengan osteoartritis, nyeri otot, nyeri sendi, sindrom nyeri myofascal dan nyeri punggung bawah karena teknik ini dapat menurunkan nyeri dan juga dapat dianggap sebagai opsi alternatif untuk memperbaiki gejala untuk pasien dengan masalah pada muskulokelektal terutama ketika efek samping dari perawatan lain seperti NSAID.

\section{DAFTAR PUSTAKA}

1. Siregar M, Dewi AP, Dewi YI, Keperawatan F. Efektifitas Kompres Air Hangat Terhadap Penurunan Nyeri Sendi penderita gout arthritis. JOM FKp. 2018;5(2):229-233.

2. World Health Organization (WHO). WHO Methods and Data Sources Global Burden of Diasese Estimates 2000-2015.; 2017.

3. Laporan Rikesda. Kementrian Kesehatan Republik Indonesia Badan Penelitian Dan Pengembangan Kesehatan.; 2018.

4. Seran Ribka H bidjuni, Franly Onibala. Hubungan Antara Nyeri Gout Arthritis Dengan Kemandirian Lansia Di Puskesmas Towuntu Timur Kecamatan Pasan Kabupaten Minahasa Tenggara. ejournal keperawatan (e-kep). 2016;4(1).

5. Mellynda Wurangian, Hendro Bidjuni V kallo. Pengaruh Kompres Hangat Terhadap Penurunan Skala Nyeri Pada Penderita Gout Arthritis Di Wilayah Kerja Puskesmas Bahu Manado. J Unsarat. Published online 2014. https://ejournal.unsrat.ac.id/index.php/jkp/artic le/view/5264/4777 
6. Therkleson T. Ginger compress therapy for adults with osteoarthritis. J Adv Nurs. 2010;66(10):2225-2233. doi:10.1111/j.13652648.2010.05355.x

7. Bundhwar V. Khasiat Rahasia Jahe Dan Kunyit. PT. Bhuana ilmu populer; 2006.

8. Chiranthanut N, Hanprasertpong N, Teekachunhatean S. Thai Massage, and Thai Herbal Compress versus Oral Ibuprofen in Symptomatic Treatment of Osteoarthritis of the Knee: A Randomized Controlled Trial. Biomed Res Int. 2014;2014:13. doi:10.1155/2014/490512

9. Dhippayom T, Kongkaew C, Chaiyakunapruk $\mathrm{N}$, et al. Clinical effects of thai herbal compress: A systematic review and meta-analysis. Evidence-based Complement Altern Med. 2015;2015(February):14. doi:10.1155/2015/942378

10. Baeha loice noni faery, Pujiastuti M, Pane J. Pengaruh Herbal Compress Ball Terhadap Penurunan Nyeri Otot Pada Lansia Di Upt
Pelayanan Sosial Lanjut Usia Binjai. J Mutiara Ners. 2018;1(2):81-89.

11. Izza S. Perbedaan Efektifitas Pemberian Kompres Air Hangat dan Pemberian Kompres Jahe Terhadap Penurunan Nyeri Sendi pada Lansia di Unit Rehabilitasi Sosial Wening Wardoyo Ungaran. Skripsi Progr Stud Keperawatan STIKES Ngudi Waluyo Ung. Published online 2014.

12. Laosee O, Sritoomma N, Wamontree $P$, Rattanapan C, Sitthi-Amorn C. The effectiveness of traditional Thai massage versus massage with herbal compress among elderly patients with low back pain: A randomised controlled trial. Complement Ther Med. 2020;48(June 2019):102253. doi:10.1016/j.ctim.2019.102253

13. Boonruab J, Nimpitakpong N, Damjuti W. The Distinction of Hot Herbal Compress, Hot Compress, and Topical Diclofenac as Myofascial Pain Syndrome Treatment. J Evidence-Based Integr Med. 2018;23:1-8. doi:10.1177/2156587217753451 